\title{
FORMAÇÃO CONTINUADA E TRABALHO DIDÁTICO: METODOLOGIA COM BASE NA PEDAGOGIA HISTÓRICO-CRÍTICA
}

\author{
CONTINUING EDUCATION AND TEACHING WORK: METHODOLOGY BASED ON \\ HISTORICAL-CRITICAL PEDAGOGY
}

\author{
Kleiton Ramires Pires Bezerra \\ Mestre em Educação pela Universidade Estadual de Mato Grosso do Sul - UEMS \\ Professor da REME em Campo Grande, MS - Brasil \\ kleitonramires@yahoo.com.br
}

\begin{abstract}
Resumo: O objetivo deste estudo foi analisar e tecer algumas considerações sobre os aspectos do trabalho didático, a interação educacional, os recursos pedagógicos e o espaço escolar, durante o processo de formação continuada dos professores de educação física da Rede Municipal de Ensino de Campo Grande/MS (REME). Durante acompanhamento pedagógico dos professores de educação física da REME, pela equipe de professores-técnicos de educação física da Gerência do Ensino Fundamental e Médio da Secretaria Municipal de Educação de Campo Grande/MS, houve a seguinte problemática: dificuldade dos professores de educação física na organização e sistematização de planos de aula, estabelecimento de objetivos relacionados com o trabalho didático, a explicação da metodologia utilizada e os procedimentos avaliativos - uso de instrumentos de avaliação e de categorias avaliadas. A formação continuada com base na pedagogia histórico-crítica, segundo as etapas mencionadas, se mostrou significativas, no sentido de introduzir de maneira metodológica o assunto planejamento escolar.
\end{abstract}

Palavras-chave: Formação continuada. Trabalho didático. Pedagogia histórico-crítica.

Abstract: The purpose of study was to analyze and make some considerations about aspects of the didactic work, educational interaction, pedagogical resources and school space during the training process of the physical education teachers of the Municipal Education Network of Campo Grande / MS (REME). During the pedagogical accompaniment of REME physical education teachers, by the team of physical education teachers and technicians of the Management of Primary and Secondary Education of the Municipal Campo Grande / MS, there were the following problems: difficulty of REME teachers in the organization and systematization of lesson plans, establishment of objectives related to didactic work, explanation of the methodology used and evaluation procedures - the use of evaluation instruments and categories evaluated. Continuing education on the basis of historical-critical pedagogy, according to the aforementioned steps, were shown to be significant, in order to introduce methodologically the subject of school planning.

Keywords: Continuing education. Didactic work. Historical-critical pedagogy.

\section{Para citar - ABNT NBR 6023:2018}

BEZERRA, Kleiton Ramires Pires. Formação continuada e trabalho didático: metodologia com base na pedagogia histórico-crítica. Cadernos de Pós-graduação, São Paulo, v. 19, n. 2, p. 48-59, jul./dez. 2020. Disponível em: https://doi.org/10.5585/cpg.v19n2.18124. 


\section{Introdução}

É por meio do trabalho que o homem obtém suas necessidades, ele age sobre a natureza, a altera, e essa proporciona a sua própria alteração. Assim, os homens agem sobre a natureza fazendo sua própria história, “[...] mas não a fazem em condições escolhidas por eles. São historicamente determinados pelas condições em que produzem suas vidas". (CHAUI, 2000, p. 534, grifo da autora).

No âmbito educacional, segundo Alves (2005) o trabalho realizado pela escola faz parte do trabalho didático, que remete a aspectos que o envolvem, a interação educacional, os recursos pedagógicos e o espaço escolar. Dessa forma, o trabalho didático:

[...] é sempre uma relação educativa que coloca, frente a frente, uma forma histórica de educador e uma forma histórica de educando (s), de outro, realiza-se com a mediação de recursos didáticos, envolvendo os procedimentos técnico-pedagógicos do educador, as tecnologias educacionais pertinentes e os conteúdos programados para servir ao processo de transmissão do conhecimento e implica um espaço físico com características peculiares, onde ocorre. (ALVES, 2005, p. 10-11).

O presente estudo analisa e tece algumas considerações sobre os aspectos do trabalho didático do processo de formação continuada realizada pela Secretaria Municipal de Educação de Campo Grande-MS (SEMED), para professores de educação física da Rede Municipal de Ensino de Campo Grande-MS (REME).

A base epistemológica, conceitual e metodológica dessa formação continuada foi a pedagogia histórico-crítica, que segundo Saviani (2013) se diferencia de outras devido ao teor crítico que possui, defende o conhecimento como resultado dos processos historicamente criados pelo homem mediante o trabalho.

\footnotetext{
Para tanto, o professor, em sala, deve se apropriar de diferentes práticas pedagógicas associadas aos pressupostos da pedagogia histórico-crítica. A formação continuada de professores da SEMED se propõe a orientar os professores com subsídios para que os mesmos possam consolidar sua base teórica pautada nessa perspectiva pedagógica, além de atualizar seus conhecimentos e instigá-los a repensar suas metodologias, sempre que se fizer necessário. (REME, 2017, p. 13).
}

Dessa forma, a formação continuada teve como objetivo propiciar subsídios para que os docentes possam materializar sua base teórica pautada na pedagogia histórico-crítica, além de atualizarem seus conhecimentos e instigá-los a repensar o aspecto didático planejamento escolar.

Para tanto, necessária a apropriação de diferentes práticas pedagógicas associadas aos pressupostos nessa perspectiva. Diante disso, pretende-se analisar e tecer algumas considerações sobre aspectos do trabalho didático, a interação educacional, os recursos pedagógicos e o espaço escolar, durante o processo de formação continuada dos professores de educação física da REME. 


\section{O planejamento escolar para a formação continuada}

A formação continuada no componente curricular educação física teve como tema norteador o planejamento escolar. A escolha dessa temática partiu de análises dos planos de aula dos professores dessa disciplina pela equipe de professores-técnicos de educação física da Gerência do Ensino Fundamental e Médio (GEFEM) da SEMED.

Nos acompanhamentos pedagógicos, os planos de aula foram analisados em conjunto com os professores de educação física da REME, no decorrer desse processo houve a seguinte problemática, a dificuldade docente na sistematização, no estabelecer dos objetivos, explicação da metodologia e procedimentos avaliativos - uso de instrumentos de avaliação e de categorias avaliadas. Sendo assim, o objetivo da formação continuada foi proporcionar aos professores estudos e conhecimentos sobre o assunto para enfrentamento da situação percebida e contribuir com o trabalho docente na busca qualitativa do processo de ensino.

O acompanhamento pedagógico preconiza aproximar as equipes da SEMED da atuação dos professores em suas realidades de tal modo que possam, de forma colaborativa, contribuir com as ações pedagógicas dos docentes que atendem às diversas áreas do conhecimento, contribuindo assim, com a formação, de maneira a incentivar um processo reflexivo que atinja o coletivo. (REME, 2017, p. 38).

O tema planejamento escolar é importante, pois possibilita ao docente tomar conhecimento das ações educacionais ocorridas durante o processo de ensino-aprendizagem, sem proceder pelo improviso, segundo Leal (2005, p. 02) "Planejar, então, é a previsão sobre o que irá acontecer, é um processo de reflexão sobre a prática docente, sobre seus objetivos, sobre o que está acontecendo, sobre o que aconteceu".

Além disso, Vasconcellos (2002) menciona que o planejamento vai ao encontro do combate à mecanização do conhecimento, da valorização de atitude criativa e de raciocínio lógico; do envolvimento e da percepção do professor da necessidade de mudança para o alcance da aprendizagem significativa, que ocorre quando se delimita previamente as ações a executar.

O tema planejamento escolar na formação continuada foi sistematizado de forma didática, conforme metodologia, com base nos estudos de Gasparin (2007), distribuída nas seguintes etapas: prática social inicial, problematização, instrumentalização, catarse e prática social final.

Segundo o autor, a prática social inicial seria o diagnóstico realizado tanto pelo professor como pelos alunos sobre a realidade daquilo que eles conhecem. $O$ professor parte do conhecimento da escola em que atua, das condições estruturais, dos materiais disponíveis. Em outras palavras, analisa os elementos que fazem parte do trabalho didático. Os alunos evidenciam seus conhecimentos prévios, avaliam até que ponto há o domínio de determinado conteúdo. O que segundo Vigotski (2001, p. 476), 
Toda a aprendizagem com que a criança se depara na escola sempre tem uma pré-história. [...] A aprendizagem escolar nunca começa no vazio, mas se baseia sempre em determinado estágio de desenvolvimento, percorrido pela criança antes de ingressar na escola.

A problematização se estabelecerá durante o planejamento, após o professor investigar os conteúdos a serem trabalhados, os saberes prévios dos alunos, as análises dos aspectos do trabalho didático que se realizou pela prática social inicial. Após, proporá questões desafiadoras aos educandos, que as responderão com base no nível de seus conhecimentos atuais sobre o assunto.

O processo de comunicação pelo professor dos conhecimentos científicos, elaborados e organizados historicamente, é a chamada instrumentalização. Nessa etapa, o conhecimento científico-cultural contrapõe ao conhecimento do senso comum, cabe ao docente mostrar o que cada conhecimento tem a contribuir.

Os educandos e o professor efetivam, aos poucos, o processo dialético de construção do conhecimento escolar que vai do empírico ao concreto pela mediação do abstrato, realizando as operações mentais de analisar, comparar, criticar, levantar hipóteses, classificar, deduzir, explicar, generalizar, conceituar etc. (GASPARIN, 2007, p. 52).

A catarse seria o momento em que os alunos e professor evidenciam e apreciam o quanto cresceram com a aprendizagem. Nessa etapa o professor une os conhecimentos planejados, no início do trabalho didático, com os conhecimentos que os alunos trouxeram e avalia seu desempenho como docente. Já os alunos farão a síntese entre aquilo que diziam saber com os conhecimentos científicos agora adquiridos. Para isso, explicitarão o que aprenderam de maneira formal, objetiva, mediante o processo de avaliação e uso de instrumentos avaliativos.

$\mathrm{Na}$ última etapa, a prática social final, o professor realiza a avaliação de todo o trabalho realizado pelos alunos e como os conteúdos ensinados podem ir para além da escola, para contribuir com o contexto social. E os alunos verificam como os conhecimentos aprendidos se transformarão em ação após as aulas.

Em suma, na metodologia exposta, os conhecimentos aprendidos no processo de ensino são construídos de maneira histórica e dialética. Mesmo que haja possível solução para um problema, novo desafio vem à tona, em um processo constante de tese-antítese-síntese, por isso, as etapas mencionadas não são estanques, mas procedimentos de ensino flexíveis, que podem ser retomados a qualquer momento pelo professor na medida da percepção da necessidade.

A seguir, apresentam-se os elementos, resultados e discussões de pesquisa realizada no âmbito escolar. Importante considerar que as abordagens e os instrumentos metodológicos utilizados obedeceram aos procedimentos éticos estabelecidos para a pesquisa científica em Ciências Humanas. 


\section{A formação continuada nas "Escolas Polo" de Campo Grande/MS}

A formação continuada ocorreu durante período de sete (7) dias, em seis "Escolas Polo" conforme divisão por região, no município de Campo Grande/MS. As atividades para os professores de educação física aconteceram em duas salas de aula, conforme o turno e o número de docentes presentes, o quadro mostra as escolas, o turno e o total de participantes:

Quadro 01 - Quantidade de professores presentes conforme escola polo e turno

\begin{tabular}{|c|c|c|c|c|}
\hline Polo & Escola & Matutino & Vespertino & Total \\
\hline I & Elpídio Reis & 60 & 20 & 80 \\
\hline II & Plínio Mendes dos Santos & 34 & 18 & 52 \\
\hline III & Professora Danda Nunes & 29 & 18 & 47 \\
\hline IV & Iracema de Souza Mendonça & 82 & 36 & 118 \\
\hline V & Desembargador Carlos Garcia de Queiroz & 52 & 21 & 73 \\
\hline VI & Eduardo Olímpio Machado & 55 & 33 & 88 \\
\hline
\end{tabular}

Com dois (2) dias de formação continuada em cada escola polo, na análise do quadro acima, o turno matutino contou com mais participantes em relação ao vespertino (em três escolas esse resultado foi mais que o dobro). Apesar da Escola Iracema e Elpídio Reis terem apresentado número de participantes superior a trinta professores, a circunstância possibilitou o trabalho em um único lugar, o pátio da escola, o que denota a possibilidade da formação ocorrer fora do ambiente de sala de aula.

Além da análise do espaço escolar, a interação educacional e os recursos pedagógicos foram avaliados, com início antes do primeiro dia de formação continuada, para diagnosticar os limites e possibilidades dos trabalhos virem a ocorrer. Após essa avaliação inicial, houve estudo em grupo pela equipe para debate sobre os resultados, à organização dos materiais de formação e das escolas polo.

No decorrer das explicações dos formadores, os professores-técnicos da GEFEM, os professores teceram suas considerações. A maioria dos docentes mencionou informações e conhecimentos acerca do tema planejamento, com relatos e sugestões para os presentes. Outra menção, mas com frequência menor do que a primeira, foram questionamentos e dúvidas sobre o tema. Além disso, os docentes aproveitaram o ensejo para tecer reclamações, como a falta de materiais pedagógicos, lúdicos e de espaços para atividades físicas.

O professor X disse: "o planejamento dá segurança para o trabalho do professor, observo meu plano para ver onde parei no conteúdo". A professora Y disse: "planejar tem muito é de burocrático, mostrar para a gestão se estamos planejando”. No relato dos dizeres dos participantes, 
que são antagônicos, mostra a contradição, o nome foi suprimido a fim de manter o sigilo, por questões éticas. Assim, esses foram substituídos por letras do alfabeto. E todas as falas foram transcritas de maneira literal.

Durante a formação continuada as seguintes ações aconteceram: os professores foram informados sobre a organização das atividades da formação e a sistemática da REME (o programa de formação, atribuições da GEFEM/educação física e os principais documentos pedagógicos utilizados na área). Com vistas a iniciar o tema planejamento escolar, os professores responderam ao questionamento sobre "o que sabem" e consideram importante mencionar sobre o tema. Foram anotadas no quadro negro, em forma de tópicos, as informações ditas. Formadores e professores levantaram problemáticas sobre o assunto, dificuldades encontradas no contexto escolar, no preenchimento do plano de aula e relacionaram os tópicos anotados com as problemáticas levantadas.

Houve apresentação de vídeo do professor Gasparin (2008) sobre a importância do "Planejamento" no âmbito escolar. Os professores foram estimulados com perguntas para comentarem o que assistiram na relação com as problemáticas levantadas e o contexto escolar. No final da formação foi entregue ficha avaliativa, para análise dos aspectos que norteiam o trabalho didático.

Todos os participantes, 458 professores de educação física, responderam a ficha avaliativa, que foi analisada posteriormente pelos formadores com vistas à manutenção ou alteração das estratégias de futuras formações e acompanhamentos pedagógicos. A ficha avaliativa formulada, com base no programa de formação, contou com cinco perguntas, sendo quatro de múltipla escolha e uma descritiva conforme os aspectos do trabalho didático mencionados. Nas quatro primeiras perguntas os professores deveriam marcar na escala de zero a dez a nota atribuída, onde zero significou totalmente insatisfeito e dez totalmente satisfeitos. A tabela 01 mostra as quatro primeiras perguntas com as notas e percentual obtido. 
Tabela 01 - Síntese com as perguntas e respostas dos professores

\begin{tabular}{|c|c|c|c|c|c|c|c|c|c|c|c|}
\hline \multirow{2}{*}{ Perguntas } & \multicolumn{11}{|c|}{ PERCENTAGEM REFERENTE ÀS NOTAS } \\
\hline & Zero & Um & Dois & Três & Quatro & Cinco & Seis & Sete & Oito & Nove & Dez \\
\hline $\begin{array}{l}\text { Em que nível o objetivo } \\
\text { foi atingido nesta } \\
\text { formação? }\end{array}$ & $0 \%$ & $0 \%$ & $0 \%$ & $1 \%$ & $1 \%$ & $2 \%$ & $5 \%$ & $14 \%$ & $32 \%$ & $20 \%$ & $\begin{array}{l}24 \\
\%\end{array}$ \\
\hline $\begin{array}{l}\text { Em que nível o } \\
\text { tema/assunto desta } \\
\text { formação está articulado } \\
\text { com o objetivo do } \\
\text { programa? }\end{array}$ & $0 \%$ & $0 \%$ & $1 \%$ & $1 \%$ & $0 \%$ & $3 \%$ & $4 \%$ & $9 \%$ & $8 \%$ & $48 \%$ & $\begin{array}{l}26 \\
\%\end{array}$ \\
\hline $\begin{array}{l}\text { Em que nível o objetivo } \\
\text { e o tema desta formação } \\
\text { estão condizentes com a } \\
\text { metodologia } \\
\text { program? }\end{array}$ & $0 \%$ & $0 \%$ & $0 \%$ & $0 \%$ & $0 \%$ & $3 \%$ & $4 \%$ & $12 \%$ & $27 \%$ & $26 \%$ & $\begin{array}{l}27 \\
\%\end{array}$ \\
\hline $\begin{array}{l}\text { Em que nível me sinto } \\
\text { apto a aplicar em sala de } \\
\text { aula as orientações desta } \\
\text { formação? }\end{array}$ & $0 \%$ & $0 \%$ & $0 \%$ & $1 \%$ & $1 \%$ & $4 \%$ & $6 \%$ & $13 \%$ & $25 \%$ & $24 \%$ & $\begin{array}{l}27 \\
\%\end{array}$ \\
\hline
\end{tabular}

Fonte: Dados de pesquisa.

Organização: $\mathrm{O}$ autor.

A primeira pergunta foi sobre a relação da formação continuada com o objetivo do programa de formação. Questionou em que nível o objetivo do programa de assegurar momentos de estudo e reflexões sobre o trabalho docente a fim de contribuir com o processo de ensino e aprendizagem, mediado por uma proposta da pedagogia histórico-crítica, foi atingido na formação continuada?

Gráfico 01 - Primeira pergunta com as respostas em percentual

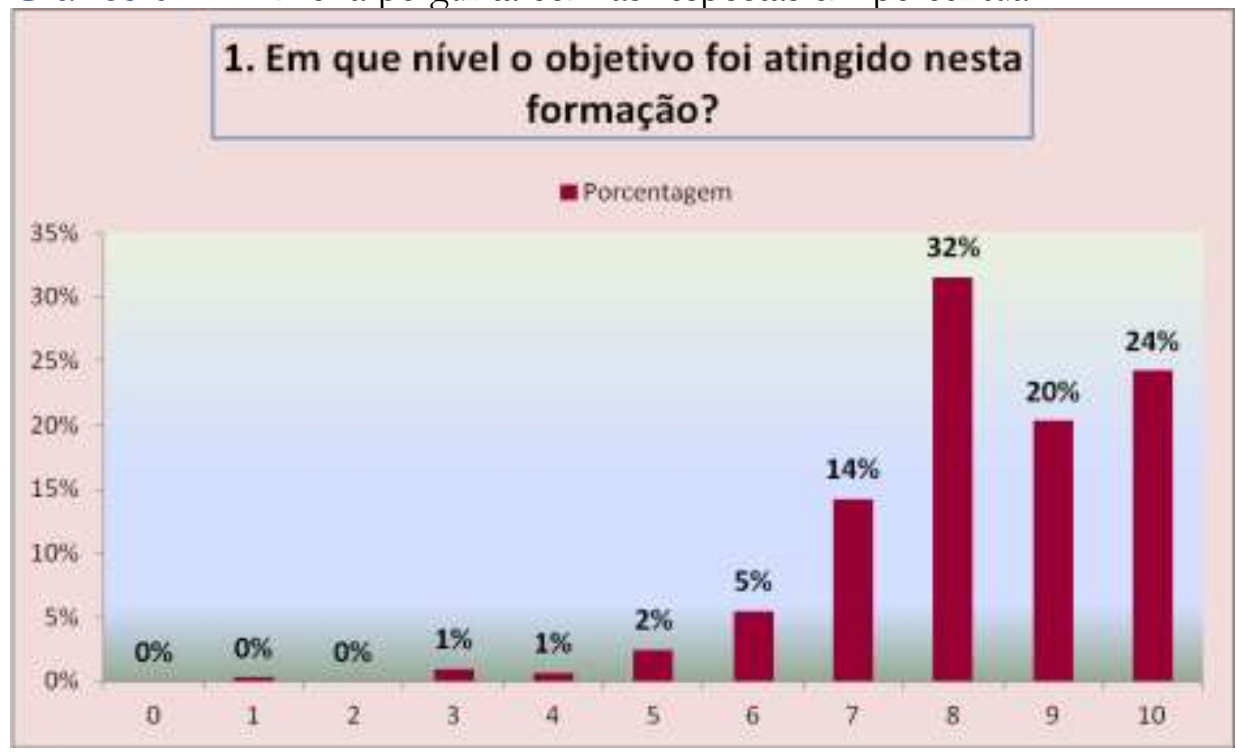

Fonte e organização: $\mathrm{O}$ autor. 
Conforme gráfico 01. Do total de respostas, a maioria respondeu com nota acima de seis, na soma do percentual da nota sete a dez, o valor foi de noventa por cento. A nota oito foi a que teve maior percentual, trinta e dois por cento. Já a soma do percentual das notas de zero a seis, o valor foi de aproximadamente dez por cento. Nas notas de zero a cinco, a porcentagem não foi significativa.

A segunda pergunta relacionou o tema abordado com o objetivo do programa. Questionou em que nível o tema da formação estava articulado com o objetivo do programa?

Gráfico 02 - Segunda pergunta com as respostas em percentual

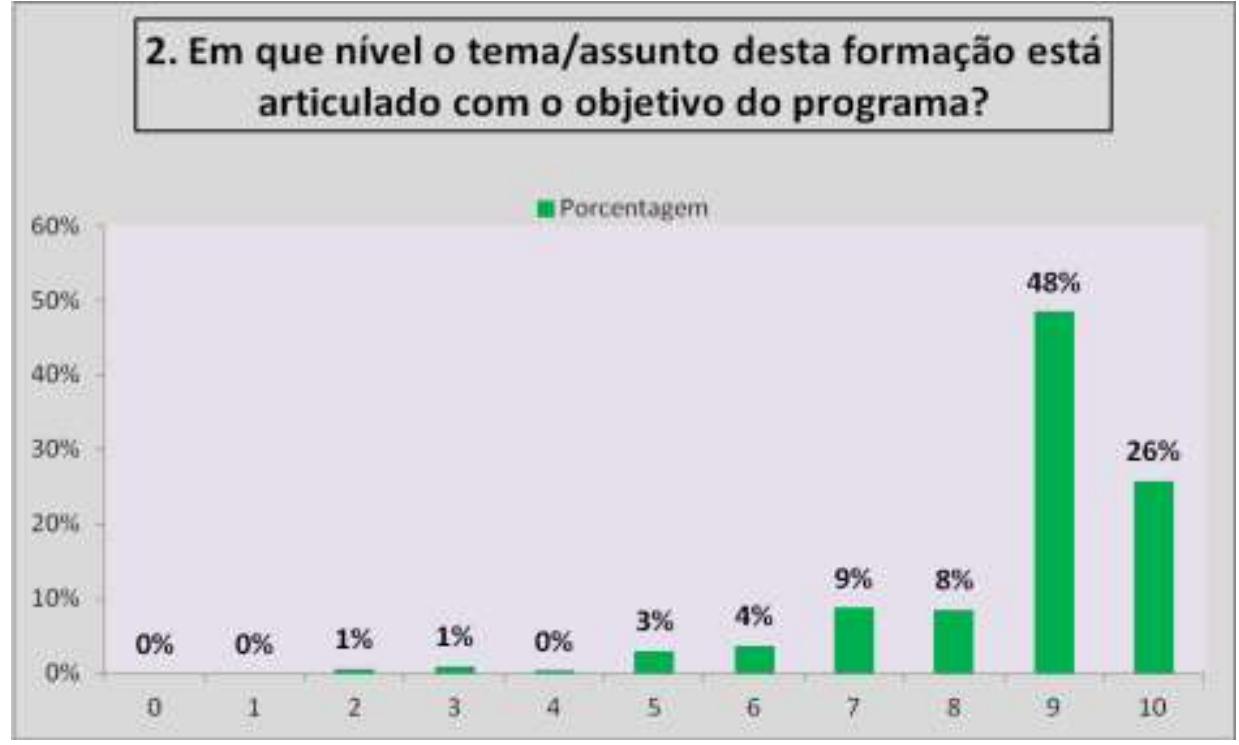

Fonte e organização: $\mathrm{O}$ autor.

Conforme gráfico 02. Número significativo de professores, quarenta e oito por cento, responderam com a nota oito. Em segundo lugar, vinte e seis por cento com a nota dez. Na soma do percentual das notas de zero a oito, o valor foi de aproximadamente vinte e seis por cento.

A terceira pergunta relacionou o objetivo e tema da formação com a metodologia do programa, que deve articular discussões junto ao grupo de professores e demais profissionais da educação, das diversas áreas do conhecimento, no sentido de evidenciar o modo como conduzem o trabalho pedagógico, para que as orientações teórico-metodológicas da REME possam ser problematizadas, instrumentalizadas e reelaboradas. Questionou em que nível o objetivo e o tema da formação foram condizentes com a metodologia do programa? 
Gráfico 03 - Terceira pergunta com as respostas em percentual

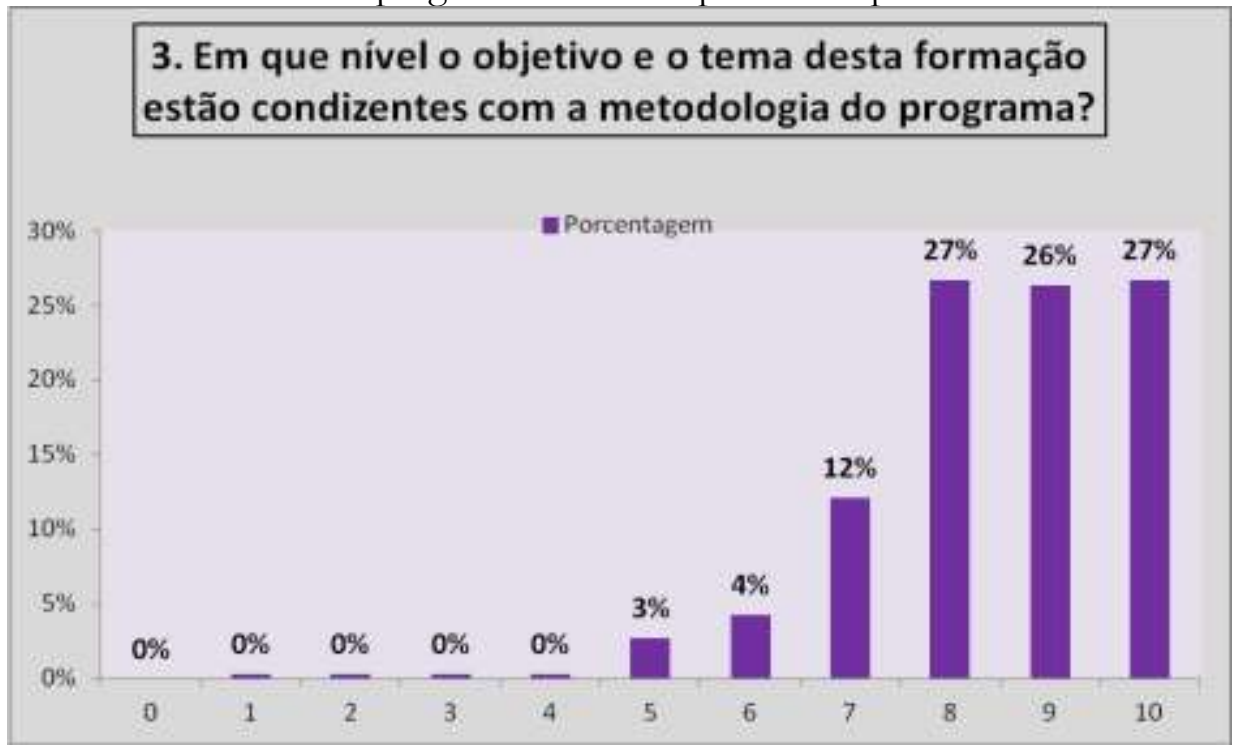

Fonte e organização: $\mathrm{O}$ autor.

Conforme gráfico 03. A maioria dos professores, oitenta por cento, responderam com as notas de oito a dez. Esses valores foram semelhantes entre si, em torno de vinte e sete por cento. Já os professores que atribuíram notas de zero a sete, a soma foi de aproximadamente vinte por cento, com a insignificância das notas de zero a quatro, menos de um (1) por cento.

A quarta pergunta questionou o professor sobre a aplicabilidade dos conhecimentos adquiridos na formação no contexto de sala de aula: Em que nível me sinto apto a aplicar em sala de aula as orientações dessa formação?

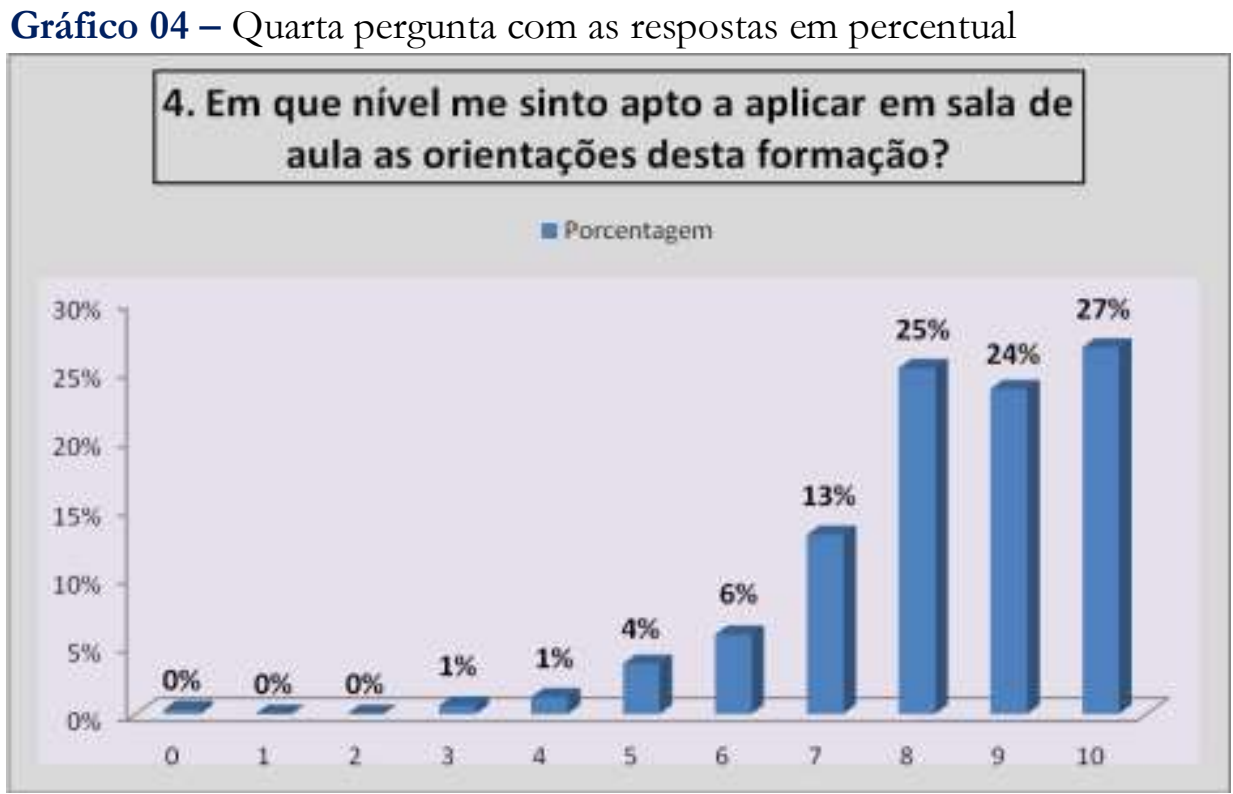

Fonte e organização: $\mathrm{O}$ autor. 
Conforme gráfico 04. Similar aos resultados da pergunta anterior, na quarta pergunta a maioria dos participantes responderam com nota acima de sete. A soma do percentual das notas de oito a dez foram de setenta e seis por cento, bem superior à soma das notas de zero a sete, aproximadamente vinte e cinco por cento.

$\mathrm{Na}$ quinta e última pergunta os professores responderam a seguinte questão: Relate abaixo sugestões, elogios ou reclamações, sua participação é sempre bem-vinda. No relato das respostas, o nome de todos os participantes foi suprimido a fim de manter seu sigilo por questões éticas. Assim, esses foram substituídos por números cardinais. E todas as respostas foram transcritas de maneira literal, conforme a escrita dos professores.

A maioria das respostas nessa questão foi referente ao aspecto sugestões, como a do professor 01: "Gostaria que tivesse mais aulas práticas da pedagogia histórico-crítica". Além dessa, o professor 02 respondeu: "É melhor intercalar o exposto com mesa redonda e momentos lúdicos".

Houve outras sugestões, como mudar o local de formação, repassar os conteúdos para a equipe técnica-pedagógica da escola, mais aulas práticas, separar a formação entre professores "novos" e "antigos", separar os professores dos anos iniciais e finais do Ensino Fundamental, enviar anteriormente por email os textos que serão trabalhados na formação e continuar com a proposta de formação, mas com outras temáticas.

O segundo aspecto mais mencionado foram elogios. Como nos dizeres da professora 03: "É minha primeira formação, gostei de tudo e achei super importante. Me ajudou a tirar dúvidas e me ajudou muito a fazer plano de aula. Muito Obrigada!". E da professora 04: "Muito bem estruturado a metodologia e a didática de acordo com o objetivo da formação continuada". Outros elogios foram mencionados, como: o momento foi satisfatório, os conteúdos foram relevantes, a formação sanou as dúvidas e formadores excelentes.

Referente às reclamações, o professor 05 disse: "local de formação pequeno e com pouca ventilação". Além desse, o professor 06 mencionou que: "Os professores participantes precisam ser mais objetivos, específicos em suas perguntas". Houve outra reclamação a de que o tema já havia sido trabalhado em outro momento.

$\mathrm{Na}$ análise dos resultados apresentados, em relação com os aspectos do trabalho didático, as notas atribuídas remetem a afirmação que a formação continuada alcançou o objetivo do programa de assegurar momentos de estudo e reflexões sobre o trabalho docente a fim de contribuir com o processo de ensino e aprendizagem, mediado por uma proposta da pedagogia histórico-crítica. 
Conforme o resultado apresentado, o tema planejamento, como proposta de estudo, manteve-se articulado com o objetivo do programa já mencionado. O tema e o objetivo da formação foram condizentes com a metodologia proposta pelo programa, de articular debates entre os professores, no sentido da ênfase no modo como conduzem o trabalho didático, com os elementos da práticas sociais, problematização e instrumentalização.

Há a possibilidade dos conhecimentos da formação continuada servirem para o ensino do professor no contexto escolar, o que caracteriza que o momento de estudo foi significativo para a atuação docente. Além disso, houve mais sugestões e elogios do que reclamações sobre o evento. Os motivos para isso são diversos, como o receio de se expor de maneira contrária aos fatos.

\section{Considerações finais}

O trabalho didático do professor no processo de ensino-aprendizagem altera o contexto escolar e o próprio docente. A interação educacional, os recursos pedagógicos e o espaço escolar fazem parte desse contexto. A formação continuada com base na pedagogia histórico-crítica, em específico, segundo as etapas: prática social inicial, problematização, instrumentalização, catarse e prática social final se mostraram significativas, no sentido de introduzir de maneira metodológica o assunto planejamento.

O processo metodológico para o trabalho didático, no caso em estudo, o planejamento, necessita da análise universal, ampla, conforme os aspectos econômicos, políticos e sociais, na consideração de sua complexidade e contradição que remetem os estudos, e que não se resume a divisão em etapas, a singularidade, definições que separam a relação do todo com suas partes.

No repensar as ações de formação e acompanhamento pedagógico, os resultados do processo e da avaliação apresentados serviram para modificação na atuação da equipe GEFEM, na ênfase dos conhecimentos prévios dos professores da REME para elaboração das atividades de formação continuada e na forma de verificação do acompanhamento pedagógico, mudança no instrumento de registro dos planos de aula, com foco no aspecto qualitativo do que quantitativo.

Os registros da equipe de educação física sobre a dificuldade dos docentes na organização, sistematização, objetivos, metodologia e procedimentos avaliativos - uso de instrumentos de avaliação e de categorias avaliadas - no plano de aula, estão em processo de produção e análise dos dados. Até o momento o resultado se mostrou satisfatório na elaboração, forma de distribuição e preenchimento do plano de aula. Na questão do conteúdo há necessidade de outras formações continuadas e acompanhamentos pedagógicos, principalmente, no "como" utilizar a pedagogia histórico-crítica, conforme metodologia apresentada em etapas didáticas. 
Espera-se que esta investigação possa contribuir na divulgação dos trabalhos sobre o objeto formação continuada na relação com o trabalho didático e auxiliar na produção de pesquisas na área e à formulação de estratégias de intervenção para a modificação das problemáticas, de dificuldade de abordagem metodológica para a introdução do estudo e didática da pedagogia histórico-crítica para as formações continuadas de diversas instituições de ensino.

\section{Referências}

ALVES, Gilberto Luiz. O Trabalho Didático na Escola Moderna: Formas Históricas. Campinas: Autores Associados, 2005.

CHAUI, Marilena. Convite à filosofia. São Paulo: Ed. Ática, 2000.

GASPARIN, João Luiz. Nós da Educação - Organização do Trabalho Pedagógico - Parte 3. Produção: TV Paulo Freire, 2008. Duração: 20min33s. Disponível em: http:/ /www. educadores.diaadia.pr.gov.br/modules/video/showVideo.php?video=13783. Acesso em: 05 de set. 2020.

GASPARIN, João Luiz. Uma Didática para a Pedagogia Histórico-Crítica. 5. ed. Campinas, SP: Autores Associados, 2007.

LEAL, Regina Barros. Planejamento de ensino: peculiaridades significativas. Revista Iberoamericana de Educación, Buenos Aires, v. 37 n. 03, p. 1-7, 2005. Disponível em: https: //rieoei.org/RIE/article/view/2705. Acesso em: 05 de set. 2020.

REME. Secretaria Municipal de Educação. Programa Educação em foco: múltiplas dimensões da formação continuada, 2017-2020. Campo Grande-MS, [s.n.], 2017.

SAVIANI, Dermeval. Pedagogia histórico-crítica: primeiras aproximações. 11. ed. Campinas, SP: Autores Associados, 2013.

VASCONCELLOS, Celso dos Santos. Coordenação do trabalho pedagógico: do projeto político pedagógico ao cotidiano da sala de aula: São Paulo. Libertad. 2002.

VIGOTSKI, Lev Semyonovich. Psicologia pedagógica. São Paulo: Martins Fontes, 2001. 